\title{
Network Structure in Service Ecosystems: An Empirical Study in the Region of Campania
}

\author{
Marco Ferretti ${ }^{1}$, Eva Panetti ${ }^{1}$, Adele Parmentola ${ }^{1} \&$ Annamaria Sabetta ${ }^{1}$ \\ ${ }^{1}$ Department of Management and Quantitative Studies, Parthenope University, Naples, Italy \\ Correspondence: Eva Panetti, Parthenope University of Naples, Department of Management and Quantitative \\ Studies, via Generale Parisi 13, 80132 Naples, Italy. E-mail: eva.panetti@uniparthenope.it
}

Received: August 1, 2019

Accepted: August 30, 2019

Online Published: September 5, 2019

doi:10.5539/ijbm.v14n10p61

URL: https://doi.org/10.5539/ijbm.v14n10p61

\begin{abstract}
The objective of this study is that of exploring the relational dimension of service ecosystems with specific regard to the structure of their networks, by conducting a social network analysis. In particular, this work attempts to primarily unveil which types of network configurations (i.e., open, closed or small words) are typical of service ecosystems. Secondly, we explore the nature of the most central actors in these networks. To these purposes, we conduct an empirical study in the Region of Campania (Southern Italy) by analyzing six regional service ecosystems in different sectors. We gathered data from the PONREC platform (Programma Operativo Nazionale "Ricerca e Competitività" 2007-2013) in order to map links among the actors in all six ecosystems. Main results show that universities and research institutions occupy brokering positions within the service ecosystems' networks. This, in turn, suggests the efficacy of public regional initiatives in favoring the establishment of forms of collaboration between organizations of different nature. Finally, our findings show that service ecosystems are characterized by open and small world network configurations. This paper contributes to the literature focused on service ecosystems' networks by providing an empirical and quantitative approach to the analysis of their relational characteristics.
\end{abstract}

Keywords: service ecosystems; inter-organizational relationships; social network analysis; Southern Italy; S-D logic

\section{Introduction}

The evolution of Service-Dominant Logic (S-D) logic has recently been marked by the introduction of the service ecosystem perspective (Lusch \& Vargo 2014) to identify a specific type of critical flow i.e., mutual service provision. Specifically, a service ecosystem is defined as "a relatively self-contained, self-adjusting system of resource-integrating actors connected by shared institutional arrangements and mutual value creation through service exchange" (Vargo \& Lusch 2016, pp. 10-11). The introduction of a service ecosystem perspective (Vargo \& Lusch 2004) provides an analytic tool to explore how value co-creation depends upon (and contributes to) the social context through which it is derived in systems of service-for-service exchange-i.e., service systems.

However, differently from the notion of "service systems" (e.g. Maglio et al. 2019) used to describe "a configuration of people, technologies and other resources that interact with other service systems to create mutual value", the "service ecosystem" stresses the role of institutions, more than technology, in the system development process and in connecting individuals and technology itself (e.g., see Barile \& Polese, 2010; Vargo \& Akaka, 2012). The idea that within service ecosystems value cocreation is coordinated thanks to actor-generated institutions and institutional arrangements suggests that "these dyadic interactions do not take place in isolation, but rather within networks of actors, of which the dyad is just a part" (Vargo \& Lusch, $2017 \mathrm{p}$. 49) and emphasizes that the benefit (value) realized by a beneficiary (e.g., a "customer") occurs through integration of the resources from many sources, understood as holistic experiences. However, differently from typical network conceptualizations (Granovetter (1973), Burt (1992) Achrol \& Kotler, 1999), in S-D logic, (i) network connections represent service-for-service exchange, rather than just connections of resources, people, or product flows; thus, actors are linked by common, dynamic processes (service provision), and (ii) the actors are defined not only in terms of this service provision (resources applied for benefit) but also in terms of the resource-integration activities that the service exchange affords (Vargo \& Lusch, 2017). This in turn, suggests 
that the interdependent relationships among service providers and service beneficiaries within systems of service vary widely in terms of organizations types (Ostrom, 2010), strength of relationships (Granovetter, 1973), and networks' configuration (Chandler \& Wieland, 2010). However, despite the recognized importance of the relational dimension in service ecosystems, there is a scant attention within literature in the field to the empirical application of such perspective and the consequent use of social network analysis to the study of service ecosystems. The adoption of a social network approach has demonstrated to be very helpful in order to analyze different types of ecosystems as it allows the identification of the actors involved and their relationships, as it has been empirically demonstrated by literature on the relational dimension of innovation ecosystems (Ahuja 2000, Still et al., 2013; Kajikawa et al. 2015; Russell et al. 2015; Balland et al. 2013; Casanueva et al. 2015; Xie et al, 2014; Salavisa et al. 2015; Li et al. 2013; Eisingerich et al. 2010, 2012; Owen-Smith \& Powell, 2004; Broekel \& Mueller, 2017). Therefore, we believe that this approach can equally be implemented for the study of service ecosystems by providing the whole picture of the value co-creation networks (Enquist et al., 2015) and allowing to derive evidence-based proposition about the optimal network configuration. In this light, this paper aims to explore the characteristics of network structure in service ecosystems, by adopting a social network approach. More specifically, we explore: RQ1. What are the network structural characteristics of a service ecosystem? RQ2. Which is the nature of the most central actors in service ecosystems' networks?

To these purposes, we conduct an empirical study in the Region of Campania (Southern Italy) by analyzing six regional service ecosystems in different sectors. We gathered data from the PONREC platform (Programma Operativo Nazionale "Ricerca e Competitività" 2007-2013) in order to map links among the actors in all six ecosystems. Main results show that universities and research institutions occupy brokering positions within the service ecosystems' networks. This, in turn, suggests the efficacy of public regional initiatives in favoring the establishment of forms of collaboration between organizations of different nature. Finally, our findings show that service ecosystems are characterized by open and small world network configurations. This paper contributes to the literature focused on service ecosystems' networks by providing an empirical and quantitative approach to the analysis of their relational characteristics.

The remainder of the paper is organized as follows: section two reviews extant contributions adopting a social network approach to explore system's configuration. Section three illustrates the research strategy adopted for addressing the theoretical gap and the research techniques implemented for the empirical case study of service ecosystems in the Region of Campania. Main results are reported and discussed in section four and five, before concluding.

\section{Theory}

In general, S-D logic argues that (i) service is the basis of exchange, (ii) value is always co-created, (iii) all social and economic actors are resource integrators, and (iv) value is always phenomenologically determined by a service beneficiary (Vargo, 2008). On this basis, Vargo and Lusch (2011) have recently broadened their perspective on service-for- service exchange by developing the concept of service ecosystem. This concept emphasizes on the one hand, the systemic nature of value cocreation and on the other, it highlights the importance of institutions (rules, norms, meanings, symbols, practices) and institutional arrangements (interdependent assemblages of institutions), suggesting that these are a key driver of value cocreation interactions (Edvardsson et al., 2014; Vargo \& Akaka, 2012). Value cocreation is a core concept of S-D logic (Vargo \& Lusch, 2008) and it is defined as "benefit realized from integration of resources through activities and interactions with collaborators in the customer network" (McColl-Kennedy et al., 2012). According to this perspective, resources do not have value per se. Indeed, value is co-created by actors when resources are used and combined through different modalities (Chandler \& Vargo, 2011). Therefore, institutional or social norms are key in order to create a common environment for value cocreation for the whole community of different actors within the ecosystem, especially at the macro level that is characterized by shared values, norms and rule that, in turn, enable and constrain meso and micro level actors (Lusch \& Vargo, 2014). In addition to the focus on institutions, the service ecosystem perspective brings new insights into the idea of value cocreation as a result of the interaction among multiple actors (Lusch \& Vargo, 2014), and as part of a process of interdependencies, adaptation, and evolution (Frow et al., 2014). Indeed, service ecosystem perspective contrasts with the traditional focus on dyadic relationships among customers and service providers by emphasizing many-to-many interactions among multiple stakeholders (Gummesson, 2007). In this sense, the "service ecosystems" idea is similar to the "service systems" concept of service science (e.g., Maglio et al., 2009), defined as "a configuration of people, technologies, and other resources that interact with other service systems to create mutual value", which is also grounded in S-D logic. However, the service systems approach evolved into one of service ecosystems, as researchers in the service community began to specialize in specific types of service system 
entities: not just people and businesses, but also universities and social enterprises (Spohrer et al., 2013; Tracy \& Lyons, 2013), things, and people (Ng \& Wakenshaw, 2017). As a consequence, an ecosystem perspective is key to understand the holistic dynamics of complex systems, that requires a shift from a firm-centered perspective to one that takes into account of the whole context of a complex world (Gummesson, 2007).Vargo and Lusch (2016) have enhanced this discussion even further, by using the term "actor" for system entities and the word "ecosystem" term to convey the idea of actor- environmental relationship as mutual service provision that is adaptive, self-adjusting and governed by reciprocal value creation and common institutional arrangements. In this sense, actor collaboration is essential (Moeller et al., 2013), in order to increase resource density, improve the set of available resources and enhance the overall value created. The idea that within service ecosystems value cocreation is coordinated through actor-generated institutions suggests that "these dyadic interactions do not take place in isolation, but rather within networks of actors, of which the dyad is just a part" (Vargo \& Lusch, 2017 p. 49). Consequently, the relationships between service providers and service beneficiaries within systems of service vary widely in terms of organizations' types (Ostrom, 2010), strength of relationships (Granovetter, 1973), and networks' configuration (Chandler \& Wieland, 2010). Our paper tries to investigate this latter aspect network configuration - of a service ecosystem by adopting the Social Network Analysis (SNA) approach. SNA has been widely implemented for the sociological study of individuals and organizations (Wasserman \& Faust, 1994; Welser et al., 2007), as well as for the assessment of nested structures among the actors within the network (Moody \& White, 2003; Halinen et al. 2012) so we believe that this approach could be equally implemented for the analysis of the relational dimension of service ecosystems. In fact, by using a social network approach it is possible to gain insight about the whole picture of the value co-creation networks (Enquist et al., 2015) and consequently, to derive evidence-based propositions about the optimal network configuration. Network theory is generally characterized by two opposite arguments regarding the preferable network structure i.e., structural holes versus closed networks. These two perspectives present contrasting visions about the most desirable network structure to the aim of social capital creation. On the one hand, the closure argument (Coleman, 1990) suggests that social capital is more likely to be accumulated within a network in which the actors are tightly connected one another. On the other hand, the structural hole argument (Burt, 2002) maintains that social capital accumulation is rather the result of a more open network structure, in which certain actors hold brokering positions among networks' groups that would be otherwise disconnected. Coleman $(1988,1990)$ is one of the most prominent authors of the closure argument. His view emphasizes the importance of strong ties as they encourage the emergence of cooperative mechanisms; promote the development of shared social norms and trust and uncertainty reduction. Typically, closed and cohesive networks are characterized by frequent, reciprocal and repeated interactions where the involved parties usually have the possibility to cross-check information resulting from direct ties by the means of indirect paths in the network (Cassi et al., 2012). The combination of these properties is deemed to generate trust mechanisms within partnerships of collaboration (Walker et al., 1997; Buskens, 2002; McEvily et al., 2003) which in turn, strengthen the motivation and level of commitment to share knowledge within the relationship (Reagans \& McEvily, 2003), with specific regard to the exchange of complex as well as sensitive knowledge (Zaheer \& Bell, 2005). On this subject, Gargiulo \& Benassi (2000) and Beckman et al. (2004) show how in situations of high levels of risk, market uncertainty and costs related to opportunistic behavior, actors tend to prefer to embed themselves in dense and close network structures, as in the case of US venture capital networks (Sorenson and Stuart, 2008). The repeated exchange among stable members is deemed to improve coordination and access to social capital. Therefore, the availability of social capital turns out to be function of the closure of the network surrounding them. In Coleman's view, closed networks are the source of social capital as they provide a better access to information and discourage opportunistic behavior (Coleman, 1988; Walker, Kogut, \& Shan, 1997; Rowley, Behrens, \& Krackhardt 2000) as "closure facilitates sanctions and makes less risky for people in the network to trust one another" (Burt, 2002) due to the threat of reputation loss. Cohesive and dense networks are likely to have similar information and thus provide redundant information benefits. Additionally, this perspective suggests that redundant ties among firms may result in a collective action's resolution of the problems. Conversely, Burt's structural hole theory $(1992,1997,2002)$ emphasizes the role of weak ties and the lack of network closure. The argument considers social capital as a function of brokerage opportunities and relies on concepts that originated in sociology during the 1970s, namely the strength of weak ties (Granovetter, 1973) and betweenness centrality (Freeman, 1977). This perspective can be considered as an extension of the Granovetter's argument about the strength of weak ties that suggests that a greater amount of information is more easily obtained through weak rather than strong and long-term relationships. More specifically, the high costs related to the maintenance of close relationships would limit the number of "ties" that an organization can have. Secondly, since weak ties do not generally encompass a regular-basis interaction, they may access to less redundant information compared to strong ties. Network 
betweenness is an index proposed by Freeman that indicates the extent to which a node brokers indirect connection among all other nodes in the network. The holes in social structure, i.e. Structural holes, provide a competitive advantage for those actors whose connections span the holes, which in turn act as buffers separating non-redundant sources of information. Therefore, structural holes provide the possibility of brokering the flux of information between the nodes and "control the projects that bring together people from opposite sides of the hole" (Burt, 2002). Additionally, firms who are positioned in structural holes may have more opportunity to brokerage activities, by serving as bridges among relatively unconnected parts of the network. In the end, the availability of information is not limited to the function of a firm's ties only, but also to those retained by third parties, i.e. network configuration. Critical links represent another class of ties that has gained increasing attention in the network literature. These links have the function of connecting poorly or otherwise disconnected sub-networks in a way that when, for some reason, they dissolve, then the entire network collapses, including the process of knowledge transfer among its members. Due to the critical links' function to connect sparsely linked parts of the network, they have often been referred to as "bottlenecks" (Sytch, Tatarynowicz, \& Gulati, 2012) or "bridges" (Glückler, 2007). Watts and Strogatz (1998) suggest that the structure of networks may present the benefits of both strong and weak ties. For this specific configuration, the authors refer to the Small Worlds (Travers \& Milgram, 1967), i.e. particular types of networks characterized by a shorter path length and a higher clustering coefficient. In other words, in these networks the actors are close to almost all other elements through a smaller number of interconnecting paths, despite the large number of nodes. The first property of Small Worlds - shorter path length - sustains network closure and for this reason, it is expected that knowledge and information circulate through the small world network more easily and quickly. Thus, a network with a small path length can be considered as one with fewer structural holes (benefit of weak ties). On the other hand, the second property higher clustering coefficient - suggests that a larger social capital is accumulated, which leads to collective problem resolution (benefit of strong ties). However, following Ahuja (2000), the optimal structure of inter-firm networks ultimately depends on the objectives of the network members. The high level of density and of information redundancy within local cliques' relationships, allows for the establishment of a shared language that increases mutual trust and facilitates the transfer of tacit information between the actors; the shortcuts connecting local cliques to other poorly connected segments of the network, contribute to fastest dispersion and combination of new information among the network's actors and allow for the penetration of new knowledge sources, which in turn alleviates the risk of lock-in that are typical of densely connected cliques (Breschi \& Catalini, 2010; Cowan \& Jonard, 2004). Social Network Analysis (SNA) has been widely implemented for the sociological study of individuals and organizations (Wasserman \& Faust, 1994; Welser et al., 2007), as well as for the assessment of nested structures among the actors within the network (Moody \& White, 2003; Halinen et al. 2012). In particular, studies within economic geography have paid increasing attention to relational issues (Dicken et al., 2001; Bathelt \& Gluckler, 2003; Yeung, 2005) and provided a rich narrative on spatial dynamics of evolution. This study aims to explore which are the network structural characteristics of a service ecosystem and which is the nature of the most central actors in service ecosystems' networks.

\section{Method}

In order to answer our research questions, we develop a SNA in six service ecosystems in the Region of Campania. The main purpose of the SNA is to study entire social structures (complete networks) or local networks (ego-centered networks) by identifying and analyzing the links between the individuals or organizations representing the nodes of the network and it has been widely used for the analysis of ecosystems' relational structure. We find that the region of Campania is an interesting case of study as it has been concerned in the last years with a strong commitment of regional government institutions in promoting initiatives to favor multi-actor networks to promote processes of value cocreation in different industrial domains, in line with the priority European development objectives. In this vein, the Region has implemented the Research and Competitiveness Operative National Plan (PONREC) that is one of the seven Italian programs financed for the 2007-2013 period by the European Union (EU), through the Structural Funds, to promote "convergence", i.e. the growth of regions whose development is lagging behind (regions whose per capita Gross Domestic Product is less than $75 \%$ of the EU average): Calabria, Campania, Puglia and Sicily. The PON R\&C finances projects in the fields of scientific research, technological development, competitiveness and industrial innovation and has a budget of more than 6 billion euros. The program targets six industrial areas namely Transport \& Logistics, Cultural Heritage Agri-Food, Clean Tech, Energy, Life Sciences. To the purpose of our analysis we analyses six regional networks, corresponding to the above industrial areas.

In order to build our six networks, we considered the co-participation to the same regional project as a proxy for a service-for-service relationship and consider as a tie within our network. To build our relational data, we used 
the official PONREC platform which provides information about all projects that have been funded within the region by FESR (European Regional Development Fund) funds, classified by area of specialization for the period 2007-2013. Each of the projects has been assigned a numeric code and a reference name. Secondly, for each network, we selected only those projects falling in the corresponding domain. Then, for each project we selected only those beneficiaries located in Campania Region. Finally, we were able to select 85 regional projects in which are involved 141 organizations for the Transport and Logistics (T\&L), while we selected 24 Projects with 73 organizations for the Cultural Heritage IE (CH), for Life Sciences (LS) we selected 38 projects with 59 actors, also for Agri-food (AGR) we collected all the projects (13) in which are involved 37 organizations, the Energy sector (EN) counts 24 projects with 72 actors, finally, 62 actors are involved in the Clean Tech sector (CT) with 23 projects (Table 1). Each organization constitutes a node in our network and we considered whether these organizations co- participate in one of the projects to build the edges of the networks. To present data in a visual form and compute structural network metrics we used NodeXL, an interactive network analysis software that employs a number of key functionalities used for visual network analytics. We used a force-driven algorithm where nodes repel each other and edges pull the connected nodes together to achieve a better understanding of the spatial structure of relationships (Russell et al., 2015). In graph theory, force-driven layout reveals the macro-level structure of the network including the key clusters and brokers in the network, and potential structural holes (Burt, 1992).

Table 1. Regional Service Ecosystems

\begin{tabular}{llll}
\hline & N. of Actors & N. of Relationships & N. of projects \\
\hline Transport \& Logistics (T\&L) & 141 & 559 & 85 \\
Cultural Heritage (CH) & 73 & 358 & 24 \\
Agrifood (AGR) & 37 & 79 & 13 \\
Clean Tech (CT) & 62 & 189 & 23 \\
Energy (EN) & 72 & 194 & 24 \\
Life Sciences (LS) & 59 & 155 & 38 \\
\hline
\end{tabular}

Note. The table reports main information regarding the number of actors, relationships and projects of each of the sampled networks.

\section{Results and Discussions}

Our networks present a varying size, in terms of total number of nodes (T\&L showed the maximum value with 141 nodes, while Agrifood ecosystems is the smallest network with 37 nodes); total number of edges (ranging from 79 to 551) and diameter (values range from 4 to 5). In order to explore the configuration of the networks we computed structural and positional network metrics for each of the six clusters under analysis (Table n.2).

At the structural level, we calculated metrics of density and small worlds properties to gain insights about the overall configuration of the network. The density of a network at time $t$ represents the relationship between the relationships existing at time $t$ and the potentially achievable relationships at the same time. This ratio is between 0 and 1 , and for values close to 0 we interpret the network as being weakly connected, while for values close to 1 we interpret the network as strongly connected. Based on the density values resulting from the SNA, all clusters present a network with a relatively sparse structure (values ranging from 0,06 for T\&L network and 0,13 for $\mathrm{CH}$ network) (Balland et al., 2012), suggesting the presence of structural holes in both networks (Ahuja, 2000). However, the weakly connected nature of the network is counterbalanced by the low number of connected components, i.e. a maximal set of nodes, in a way that a path connects each pair of nodes. With the exception of the T\&L cluster, where the number of connected components (21) is relatively high (due to the higher number of actors), the other networks present a low number of connected components (between 6 and 3). From a small world perspective, we calculated metrics of average path length and the average clustering coefficient (Watts \& Strogatz, 1998). The average path length, represents the average graph-distance between all pairs of nodes, and it is fundamental for the evaluation of the network performance as it informs whether a node can have an easier and quicker access to other actors with less efforts, thus accessing to a larger amount of knowledge or information (Kajikawata, 2010). Generally speaking, a small value of average path length indicates a small diameter of the network, which in turns suggests that organizations in the network can pool resources through a smaller number of paths and structural holes are buried. On the other hand, clustering coefficient represents the extent to which nodes connected to $i$ are also linked to each other and the average cluster coefficient shows the system's overall connectivity based on local relationships. It is argued that small world configuration allows to benefit from both closed and open networks' advantages. In fact, while, a network with a small path length 
sustains network closure (as it allows information to circulate more easily and quickly through a less number of paths and structural holes), a network with high clustering coefficient suggests that a larger social capital is accumulated, which is a benefit of open and sparser networks. All our networks present relatively low values of average path length (between 2,12 and 2,49) and high values of clustering coefficient (ranging from 0,71 and 0,85). These results suggest that both networks present the structural characteristics of small worlds, thereby allowing the actors to benefit from the advantages of both closed and open networks.

Table 2. Metrics of network structure

\begin{tabular}{|c|c|c|c|c|c|c|}
\hline & $\mathrm{T} \& \mathrm{~L}$ & $\mathrm{CH}$ & AGR & $\mathrm{CT}$ & EN & LS \\
\hline Vertices & 141 & 73 & 37 & 62 & 72 & 59 \\
\hline Unique Edges & 551 & 354 & 79 & 169 & 194 & 153 \\
\hline Edges with & 8 & 4 & 0 & 20 & 0 & 2 \\
\hline \multicolumn{7}{|l|}{ Duplicates } \\
\hline Total Edges & 559 & 358 & 79 & 189 & 194 & 155 \\
\hline Diameter & 5 & 5 & 4 & 4 & 4 & 4 \\
\hline Graph Density & 0,06 & 0,13 & 0,12 & 0,09 & 0,07 & 0,09 \\
\hline Connected & 21 & 6 & 5 & 4 & 3 & 3 \\
\hline \multicolumn{7}{|l|}{ Components } \\
\hline Average Geodesic & 2,49 & 2,12 & 2,15 & 2,12 & 2,71 & 2,38 \\
\hline \multicolumn{7}{|l|}{ Distance } \\
\hline Average Clustering & 0,71 & 0,79 & 0,75 & 0,85 & 0,83 & 0,74 \\
\hline \multicolumn{7}{|l|}{ Coefficient } \\
\hline Average Degree & 8,92 & 9,75 & 4,27 & 5,77 & 5,39 & 5,22 \\
\hline
\end{tabular}

Note. The table reports main structural metrics for the sampled networks.

In order to identify the nature of the key actors in both network calculated metrics of network Degree centrality. Table n. 3 shows the top ten actors in terms of degree centrality scores for each network.

Degree Centrality is typically an indicator of engagement (Barabasi \& Albert, 1999) and indicates the number of connections that each actor has with the other nodes of the network. In all networks the most popular and influential nodes are universities and research centres, with particular regard to CNR, Federico II University; University of Salerno and to a lesser extent top positions are occupied by large firms (e.g. FIAT Group; Biogem). The prominent role of academic institutions suggests their key function as service provider within service ecosystems. In particular, their centrality confirms one of the key ideas of the service ecosystem perspective, that is the shift from a firm-centered perspective to one that takes into account among service system entities not only people and businesses, but also universities (Spohrer et al., 2013; Tracy \& Lyons, 2013), and more generally, the whole context of a complex world (Gummesson, 2007). Interestingly, oftentimes most central positions are occupied by research public-private aggregations (i.e. Consorzi) among academic and research institutions and private companies, suggesting the important role of these associations in promoting mutual service relationships in the sector. 
Table 3. Top ten actors in terms of degree centrality, by network

\begin{tabular}{|c|c|c|c|}
\hline \multirow{2}{*}{$\begin{array}{l}\text { Transport\&Logistics } \\
\text { Vertex }\end{array}$} & \multicolumn{2}{|r|}{ Cultural Heritage } & \multirow[b]{2}{*}{ Degree } \\
\hline & Degree & & \\
\hline Università Degli Studi Di Napoli Federico II & 48 & $\begin{array}{l}\text { Università Degli Studi Di Napoli } \\
\text { Federico II }\end{array}$ & 42 \\
\hline Università degli Studi del Sannio & 36 & $\begin{array}{l}\mathrm{CNR} \text { - Consiglio nazionale delle } \\
\text { ricerche }\end{array}$ & 38 \\
\hline Ansaldo Sts SPA & 33 & Università degli Studi di Salerno & 32 \\
\hline CNR - Consiglio nazionale delle ricerche & 33 & Tebe & 25 \\
\hline Tecnosistem S.p.A. & 31 & INNOVA & 25 \\
\hline Centro Regionale Information Communication Technology - CeRICT scrl & 28 & $\begin{array}{l}\text { CUSSMAC Consorzio Universitario } \\
\text { Salernitano su Sistemi e Metodi per } \\
\text { Aziende Competitive }\end{array}$ & 15 \\
\hline Università degli Studi di Salerno & 28 & $\begin{array}{l}\text { Consorzio Interuniversitario Nazionale } \\
\text { per IInformatica (C.I.N.I.) }\end{array}$ & 15 \\
\hline Test S.c.a r.l. & 27 & $\begin{array}{l}\text { CRMPA - Centro di Ricerca in } \\
\text { Matematica Pura ed Applicata }\end{array}$ & 15 \\
\hline Seconda Università degli Studi di Napoli & 25 & Research & 15 \\
\hline Università degli Studi di Napoli Parthenope & 25 & $\begin{array}{l}\text { CARSO - Consorzio del Centro di } \\
\text { Ricerca Avanzata per l'Ottica Spaziale, } \\
\text { la Sensoristica e l'Ottimizz }\end{array}$ & 15 \\
\hline Agrifood & & Clean Tech & \\
\hline Vertex & Degree & Vertex & Degree \\
\hline Università Degli Studi Di Napoli Federico II & & Università Degli Studi Di Napoli & \\
\hline & 14 & Federico II & 37 \\
\hline Università degli Studi di Salerno & 9 & $\begin{array}{l}\mathrm{CNR} \text { - Consiglio nazionale delle } \\
\text { ricerche }\end{array}$ & 25 \\
\hline CNR - Consiglio nazionale delle ricerche & 9 & Università degli Studi di Salerno & 13 \\
\hline Mosaico Monitoraggio Integrato S.r.1. & 6 & Fiat Group Automobiles Spa & 13 \\
\hline KES Knowledge Environment Security S.r.1 & 6 & $\begin{array}{l}\text { Centro Ricerche Fiat S.C.P.A. } \\
\text { INGV - Istituto Nazionale di Geofisica e }\end{array}$ & 11 \\
\hline Centro Regionale Information Communication Technology - CeRICT s.c.r.l. & 6 & $\begin{array}{l}\text { Vulcanologia } \\
\text { Seconda Università degli Studi di }\end{array}$ & 9 \\
\hline Consorzio Nazionale Interuniversitario per le Telecomunicazioni & 6 & Napoli & 8 \\
\hline ProdAl S.c.ar.1 & 6 & L\&R Laboratori e Ricerche S.r.l. & 7 \\
\hline De Clemente Conserve Spa & 5 & Eucentre & 7 \\
\hline Salvati Mario \& C. Spa & 5 & Dismat S.r.l. & 7 \\
\hline Energy & & Life Sciences & \\
\hline Vertex & Degree & Vertex & Degree \\
\hline Università Degli Studi Di Napoli Federico II & & CNR - Consiglio nazionale delle & \\
\hline & 32 & ricerche & 31 \\
\hline & & Università Degli Studi Di Napoli & \\
\hline Università degli Studi di Salerno & 25 & Federico II & 21 \\
\hline & & Seconda Università degli Studi di & \\
\hline CNR - Consiglio nazionale delle ricerche & 18 & Napoli & 17 \\
\hline CRMPA - Centro di Ricerca in Matematica Pura ed Applicata & 13 & Altergon Italia S.R.L. & 13 \\
\hline Universita degli Studi di Salerno & 12 & Biogem S.C.A R.L. & 12 \\
\hline Università degli Studi di Napoli Parthenope & 12 & Stazione Zoologica Anthon Dohrn & 11 \\
\hline Seconda Universita degli studi di Napoli & 11 & Bioricerche 2010 Scarl & 10 \\
\hline & & CEINGE Biotecnologie Avanzate & \\
\hline Neatec SpA & 7 & SCARL & 9 \\
\hline Consorzio S.C.I.R.E. & 7 & Università degli Studi di Salerno & 8 \\
\hline CO.EL.MO. S.p.A. & 7 & Primm Srl & 8 \\
\hline
\end{tabular}

From the observation of the network analysis results, the analysed service ecosystems appear to be characterized 
by an open and sparse network, where brokering positions are mostly undertaken by academic and research institutions. These results are in line with the strand of studies supporting the idea that a sparse network with structural holes is preferable in order to build social capital and carry out innovation activities successfully (Burt, 2002; Bresnahan, 2001; Ahuja, 2000; Xie et al., 2014). However, the high values of cluster coefficient and relatively small values for average path length in all service ecosystems under analysis, suggest that all networks' structure tend toward small world configurations, indicating that despite keeping an open structure these are still able to provide the actors with a few benefits typical of closed networks (Kajikawa et al. 2010). In particular, the high values of clustering coefficient suggest that a larger social capital is accumulated, which is a benefit of strong ties. These network structural characteristics can be partly explained by the efficacy of Regional Government initiative in stimulating routines of collaborations through various initiatives as High-Tech Districts, Public-Private Aggregations and Labs that turn into actual, consolidated and independent partnerships through which partners establish repeated relationships overtime. On the other hand, our study confirms the centrality of the academic institutions in networks. These last results can be explained by the wave of regional interventions to promote public-private partnerships in the Region to promote systemic and multi-actor processes of value co-creation. This in turn, confirms the idea that in service ecosystems value cocreation is a systemic process that is coordinated through actor-generated institutions (Vargo \& Lusch, 2017) and more in general, the key role of institutions in value co-creation processes (Vargo \& Akaka, 2012).

\section{Conclusions}

The aim of this work was that of exploring the network configuration of service ecosystems by taking empirical evidence from six service ecosystems' networks in the Campania Region (South of Italy). The social network analysis conducted on mutual service relationships among a heterogeneous sample of organizations revealed that service ecosystems are characterized by an open network, where brokering positions are mostly undertaken by academic institutions, which is in line with the studies arguing that an open structure better sustains the conduct of collaboration and valuable activities. Also, these results suggest the efficacy of Regional Government institutions in stimulating permanent inter-organizational forms of cooperation that convey to the network a small world configuration. Overall, the work contributes to the strand of literature focusing on the relational dimension of service ecosystems by proposing an empirical and quantitative approach to the study of their relational dimension. Our results could policy makers about the choices of establishing future programs and initiatives for stimulating local network formation according to the sectorial specificities. However, this work is not free from limitations. First, the sample could include a greater number of organizations within the Region in order to achieve a greater extent of validation of the results. Second, other types of inter-organizational relationships could be included in the analysis to better explore service ecosystems' network variety. Finally, a comparative study with other service ecosystems localized in different regions would contribute to the identification of industrial patterns in service ecosystems' network architecture. Future research is invited to overcome above limitations.

\section{References}

Achrol, R. S., \& Kotler, P. (1999). Marketing in the network economy. Journal of marketing, 63(4_supp11), 146-163. http://dx.doi.org/10.2307/1252108

Ahuja, G. (2000). Collaboration networks, structural holes, and innovation: A longitudinal study. Administrative science quarterly, 45(3), 425-455. http://dx.doi.org/10.2307/2667105

Balland, P. A., Boschma, R., \& Frenken, K. (2013). Proximity and innovation networks. Re-framing Regional Development: Evolution, Innovation and Transition, Routlege, Oxon, 186-200

Barile, S., \& Polese, F. (2010). Smart service systems and viable service systems: Applying systems theory to service science. Service Science, 2(1-2), 21-40. http://dx.doi.org/10.1287/serv.2.1_2.21

Bathelt, H., \& Glückler, J. (2003). Toward a relational economic geography. Journal of economic geography, 3(2), 117-144. http://dx.doi.org/10.1093/jeg/3.2.117

Beckman, C. M., Haunschild, P. R., \& Phillips, D. J. (2004). Friends or strangers? Firm-specific uncertainty, market uncertainty, and network partner selection. Organization science, 15(3), 259-275. http://dx.doi.org/10.1287/orsc.1040.0065

Breschi, S., \& Catalini, C. (2010). Tracing the links between science and technology: An exploratory analysis of scientists' and inventors' networks. Research Policy, 39(1), 14-26. http://dx.doi.org/10.1016/j.respol.2009.11.004

Broekel, T., \& Mueller, W. (2018). Critical links in knowledge networks-What about proximities and gatekeeper 
$\begin{array}{lllll}\text { organisations?. } & \text { Industry } & \text { and }\end{array}$ http://dx.doi.org/10.1080/13662716.2017.1343130

Burt, R. (2012). Structural Holes [1992]. Contemporary Sociological Theory, 204. http://dx.doi.org/10.4324/9780429494468-63

Buskens, V. (2002). Social networks and trust (Vol. 30). Springer Science \& Business Media.

Cassi, L., Morrison, A., \& Ter Wal, A. L. (2012). The evolution of trade and scientific collaboration networks in the global wine sector: A longitudinal study using network analysis. Economic geography, 88(3), 311-334. http://dx.doi.org/10.1111/j.1944-8287.2012.01154.x

Chandler, J. D., \& Wieland, H. (2010). Embedded relationships: implications for networks, innovation, and ecosystems. Journal of Business Market Management, 4(4), 199-215. http://dx.doi.org/10.1007/s12087-010-0041-5

Chandler, J., \& Vargo, S. L. (2011). Contextualization: Network intersections, value-in-context, and the co-creation of markets. Marketing Theory, 11(1), 35-49.

Coleman, J. S. (1988). Social capital in the creation of human capital. American journal of sociology, 94 , S95-S120.

Cowan, R., \& Jonard, N. (2004). Network structure and the diffusion of knowledge. Journal of economic Dynamics and Control, 28(8), 1557-1575. http://dx.doi.org/10.1016/j.jedc.2003.04.002

Dicken, P., Kelly, P. F., Olds, K., \& Wai-Chung Yeung, H. (2001). Chains and networks, territories and scales: towards a relational framework for analysing the global economy. Global networks, 1(2), 89-112. http://dx.doi.org/10.1111/1471-0374.00007

Edvardsson, B., \& Tronvoll, B. (2013). A new conceptualization of service innovation grounded in SD logic and service systems. International Journal of Quality and Service Sciences, 5(1), 19-31.

Eisingerich, A. B., Bell, S. J., \& Tracey, P. (2010). How can clusters sustain performance? The role of network strength, network openness, and environmental uncertainty. Research policy, 39(2), 239-253.

Eisingerich, A., Falck, O., Heblich, S., \& Kretschmer, T. (2012). Firm innovativeness across cluster types. Industry and Innovation, 19(3), 233-248. http://dx.doi.org/10.1016/j.respol.2009.12.007

Enquist, B., Petros Sebhatu, S., \& Johnson, M. (2015). Transcendence for business logics in value networks for sustainable service business. Journal of Service Theory and Practice, 25(2), 181-197. http://dx.doi.org/10.1108/JSTP-09-2013-0189

Freeman, L. C. (1977). A set of measures of centrality based on betweenness. Sociometry, 35-41. http://dx.doi.org/10.2307/3033543

Frow, P., McColl-Kennedy, J. R., Hilton, T., Davidson, A., Payne, A., \& Brozovic, D. (2014). Value propositions: A service ecosystems perspective. Marketing Theory, 14(3), 327-351. http://dx.doi.org/10.1177/1470593114534346

Gargiulo, M., \& Benassi, M. (2000). Trapped in your own net? Network cohesion, structural holes, and the adaptation of social capital. Organization $\quad$ science, $11(2), \quad 183-196$. http://dx.doi.org/10.1287/orsc.11.2.183.12514

Glückler, J. (2007). Economic geography and the evolution of networks. Journal of Economic Geography, 7(5), 619-634

Granovetter, M. S. (1977). The strength of weak ties. In Social networks (pp. 347-367). Academic Press. http://dx.doi.org/10.1016/B978-0-12-442450-0.50025-0

Gulati, R., Sytch, M., \& Tatarynowicz, A. (2012). The rise and fall of small worlds: Exploring the dynamics of social structure. Organization Science, 23(2), 449-471. http://dx.doi.org/10.1287/orsc.1100.0592

Gummesson, E. (2008). Extending the service-dominant logic: from customer centricity to balanced centricity. Journal of the Academy of Marketing Science, 36(1), 15-17. http://dx.doi.org/10.1007/s11747-007-0065-x

Halinen, A. (2012). Relationship marketing in professional services: a study of agency-client dynamics in the advertising sector. Routledge. http://dx.doi.org/10.4324/9780203025512

Kajikawa, Y., Takeda, Y., Sakata, I., \& Matsushima, K. (2010). Multiscale analysis of interfirm networks in regional clusters. Technovation, 30(3), 168-180. http://dx.doi.org/10.1016/j.technovation.2009.12.004 
Lusch, R. F. (2011). Reframing supply chain management: a service-dominant logic perspective. Journal of supply chain management, 47(1), 14-18. http://dx.doi.org/10.1111/j.1745-493X.2010.03211.x

Lyons, K., \& Tracy, S. (2013). Characterizing organizations as service systems. Human Factors and Ergonomics in Manufacturing \& Service Industries, 23(1), 19-27. http://dx.doi.org/10.1002/hfm.20517

Maglio, P. P., \& Spohrer, J. (2013). A service science perspective on business model innovation. Industrial Marketing Management, 42(5), 665-670. http://dx.doi.org/10.1016/j.indmarman.2013.05.007

Maglio, P. P., Vargo, S. L., Caswell, N., \& Spohrer, J. (2009). The service system is the basic abstraction of service science. Information Systems and e-business Management, 7(4), 395-406. http://dx.doi.org/10.1007/s10257-008-0105-1

McColl-Kennedy, J. R., Vargo, S. L., Dagger, T. S., Sweeney, J. C., \& Kasteren, Y. V. (2012). Health care customer value cocreation practice styles. Journal of Service Research, 15(4), 370-389. http://dx.doi.org/10.1177/1094670512442806

McEvily, B., Perrone, V., \& Zaheer, A. (2003). Trust as an organizing principle. Organization science, 14(1), 91-103. http://dx.doi.org/10.1287/orsc.14.1.91.12814

Moeller, S., Ciuchita, R., Mahr, D., Odekerken-Schröder, G., \& Fassnacht, M. (2013). Uncovering collaborative value creation patterns and establishing corresponding customer roles. Journal of service research, 16(4), 471-487. http://dx.doi.org/10.1177/1094670513480851

Moody, J., \& White, D. R. (2003). Structural cohesion and embeddedness: A hierarchical concept of social groups. American Sociological Review, 103-127. http://dx.doi.org/10.2307/3088904

Ng, I., \& Wakenshaw, S. (2018). Service Ecosystems: A Timely Worldview for a Connected, Digital and Data-Driven Economy. The SAGE Handbook of Service-Dominant Logic, 199. http://dx.doi.org/10.4135/9781526470355.n12

Ostrom, A. L., Bitner, M. J., Brown, S. W., Burkhard, K. A., Goul, M., Smith-Daniels, V., ... \& Rabinovich, E. (2010). Moving forward and making a difference: research priorities for the science of service. Journal of service research, 13(1), 4-36. http://dx.doi.org/10.1177/1094670509357611

Reagans, R., \& McEvily, B. (2003). Network structure and knowledge transfer: The effects of cohesion and range. Administrative science quarterly, 48(2), 240-267. http://dx.doi.org/10.2307/3556658

Rowley, T., Behrens, D., \& Krackhardt, D. (2000). Redundant governance structures: An analysis of structural and relational embeddedness in the steel and semiconductor industries. Strategic management journal, $21(3)$ 369-386. http://dx.doi.org/10.1002/(SICI)1097-0266(200003)21:3\%3C369::AID-SMJ93\%3E3.0.CO;2-M

Russell, M. G., Huhtamäki, J., Still, K., Rubens, N., \& Basole, R. C. (2015). Relational capital for shared vision in innovation ecosystems. Triple Helix, 2(1), 8. http://dx.doi.org/10.1186/s40604-015-0017-2

Sorenson, O., \& Stuart, T. E. (2008). Bringing the context back in: Settings and the search for syndicate partners in venture capital investment networks. Administrative Science Quarterly, 53(2), 266-294. http://dx.doi.org/10.2189/asqu.53.2.266

Sousa, C., \& Salavisa, I. (2015, September). International Knowledge Networks in Sustainable Energy Technologies: Evidence From European Projects. In European Conference on Innovation and Entrepreneurship (p. 691). Academic Conferences International Limited.

Spohrer, J. C., Kieliszewski, C. A., Lyons, K., Maglio, P. P., Sawatani, Y., \& Patrício, L. (Eds.). (2019). Handbook of service science. Springer.

Travers, J., \& Milgram, S. (1967). The small world problem. Phychology Today, 1(1), 61-67.

Tsujimoto, M., Kajikawa, Y., Tomita, J., \& Matsumoto, Y. (2015, August). Designing the coherent ecosystem: Review of the ecosystem concept in strategic management. In 2015 Portland International Conference on Management of Engineering and Technology (PICMET) (pp. 53-63)..

Vargo, S. L., \& Akaka, M. A. (2012). Value cocreation and service systems (re) formation: A service ecosystems view. Service Science, 4(3), 207-217. http://dx.doi.org/10.1287/serv.1120.0019

Vargo, S. L., \& Lusch, R. F. (2004). The four service marketing myths: remnants of a goods-based, manufacturing model. Journal of service research, 6(4), 324-335. http://dx.doi.org/10.1177/1094670503262946 
Vargo, S. L., \& Lusch, R. F. (2008). Service-dominant logic: continuing the evolution. Journal of the Academy of marketing Science, 36(1), 1-10. http://dx.doi.org/10.1007/s11747-007-0069-6

Vargo, S. L., \& Lusch, R. F. (2016). Institutions and axioms: an extension and update of service-dominant logic. Journal of the Academy of marketing Science, 44(1), 5-23. http://dx.doi.org/10.1007/s11747-015-0456-3

Vargo, S. L., \& Lusch, R. F. (2017). Service-dominant logic 2025. International Journal of Research in Marketing, 34(1), 46-67. http://dx.doi.org/10.1016/j.ijresmar.2016.11.001

Vargo, S. L., Wieland, H., \& Akaka, M. A. (2015). Innovation through institutionalization: A service ecosystems perspective. Industrial Marketing Management, 44 63-72. http://dx.doi.org/10.1016/j.indmarman.2014.10.008

Walker, G., Kogut, B., \& Shan, W. (1997). Social capital, structural holes and the formation of an industry network. Organization science, 8(2), 109-125. http://dx.doi.org/10.1016/B978-0-7506-7222-1.50013-1

Wasserman, S., \& Faust, K. (1994). Social network analysis: Methods and applications (Vol. 8). Cambridge university press. http://dx.doi.org/10.1017/CBO9780511815478

Watts, D. J., \& Strogatz, S. H. (1998). Collective dynamics of 'small-world'networks. Nature, 393(6684), 440.

Welser, H. T., Gleave, E., Fisher, D., \& Smith, M. (2007). Visualizing the signatures of social roles in online discussion groups. Journal of social structure, 8(2), 1-32.

White, D. R., Owen-Smith, J., Moody, J., \& Powell, W. W. (2004). Networks, fields and organizations: micro-dynamics, scale and cohesive embeddings. Computational \& mathematical organization theory, 10(1), 95-117. http://dx.doi.org/10.1023/B:CMOT.0000032581.34436.7b

Xie, X., Fang, L., \& Zeng, S. (2016). Collaborative innovation network and knowledge transfer performance: A fsQCA approach. Journal of business research, 69(11), 5210-5215. http://dx.doi.org/10.1016/j.jbusres.2016.04.114

Yeung, H. W. C. (2005). Rethinking relational economic geography. Transactions of the Institute of British Geographers, 30(1), 37-51. http://dx.doi.org/10.1111/j.1475-5661.2005.00150.x

Zaheer, A., \& Bell, G. G. (2005). Benefiting from network position: firm capabilities, structural holes, and performance. Strategic management journal, 26(9), 809-825. http://dx.doi.org/10.1002/smj.482

\section{Copyrights}

Copyright for this article is retained by the author(s), with first publication rights granted to the journal.

This is an open-access article distributed under the terms and conditions of the Creative Commons Attribution license (http://creativecommons.org/licenses/by/4.0/). 